\title{
Gene expression and matrix turnover in overused and damaged tendons
}

\author{
G. P. Riley \\ Head of Soft Tissue Injury and Repair Group, Rheumatology Research Unit, Addenbrooke's Hospital, Cambridge, UK \\ Corresponding author: Graham P. Riley, Head of Soft Tissue Injury and Repair Group, Rheumatology Research Unit, \\ Box 194, Addenbrooke's Hospital, Cambridge CB2 2QQ, UK. Tel: +44(0)1223 217458, Fax: +44 (0)1223 217838, \\ E-mail:gpr1003@cam.ac.uk
}

Accepted for publication 11 February 2005

Chronic, painful conditions affecting tendons, frequently known as tendinopathy, are very common types of sporting injury. The tendon extracellular matrix is substantially altered in tendinopathy, and these changes are thought to precede and underlie the clinical condition. The tendon cell response to repeated minor injuries or "overuse" is thought to be a major factor in the development of tendinopathy. Changes in matrix turnover may also be effected by the cellular response to physical load, altering the balance of matrix turnover and changing the structure and composition of the tendon. Matrix turnover is relatively high in tendons exposed to high mechanical demands, such as the supraspinatus and Achilles, and this is thought to represent either a repair or tissue maintenance function. Metalloproteinases are a large family of enzymes capable of degrading all of the tendon matrix components, and these are thought to play a major role in the degradation of matrix during development, adaptation and repair. It is proposed that some metalloproteinase enzymes are required for the health of the tendon, and others may be damaging, leading to degeneration of the tissue. Further research is required to investigate how these enzyme activities are regulated in tendon and altered in tendinopathy. A profile of all the metalloproteinases expressed and active in healthy and degenerate tendon is required and may lead to the development of new drug therapies for these common and debilitating sports injuries.
Tendon injuries and chronic tendon pain are extremely common in athletes, as well as in the general population. Despite their prevalence, these conditions are poorly understood and often do not respond well to treatment. There are many articles, which discuss the potential causes and treatment of tendon pathology (tendinopathy), but few have investigated the molecular processes underlying the condition. This review summarizes recent work investigating the molecular composition of the human tendon extracellular "matrix", and how this is altered in chronic tendinopathy. These studies have shown that the cells resident within the tendon, known as "tenocytes", are capable of synthesizing and degrading the tendon matrix, a process of "turnover" that is important in the tissue response to exercise, mechanical strain and injury. The pattern of loading (whether tensile or compressive, for example) as well as its magnitude and duration, is fundamental in the regulation of the tenocyte remodelling response. This review will highlight the role of matrix-degrading enzymes in tendon matrix turnover, and discuss their role in tendon health and disease.

\section{The etiology of tendinopathy}

Most tendinopathy is associated with multiple factors such as increased age, reduced vascular perfusion, anatomical variation (e.g. leg-length discrepancy), occupation and the level and type of sporting activity (Leadbetter, 1992; Józsa \& Kannus, 1997a; Kannus, 1997; Riley, 2004a). The pattern and duration of physical stress experienced by the tendon is generally thought to be one of the most important factors, since tendons at sites exposed to high mechanical demands are more often affected. These include the supraspinatus tendon in the shoulder, the extensor carpi radialis brevis tendon at the elbow, the patellar tendon at the knee and the Achilles at the ankle. However, most cases of tendinopathy occur in the absence of any single traumatic episode, and are associated with repeated low-level loading of the muscle-tendon unit, frequently described as "overuse" injuries (Józsa \& Kannus, 1997a).

Although once considered almost inert, the activity of the tendon cell (tenocyte) is thought to play a pivotal role in the pathology of tendinopathy. Tenocytes synthesize and degrade the tendon extracellular 
matrix, a process of matrix turnover that is normally well-regulated and essential for maintaining the structural properties of the tissue. An imbalance of matrix turnover is implicated in other degenerative conditions such as osteoarthritis (Clark \& Parker, 2003), which suggests that reduced matrix synthesis or increased matrix degradation may be targets for future drug therapy of tendinopathy.

\section{Histopathology of tendinopathy}

The structure and histology of tendon and tendinopathy have been described in detail elsewhere and only general features are discussed in this review the reader is recommended to refer to the following sources for more information (Kannus \& Józsa, 1991; Åström \& Rausing, 1995; Jarvinen et al., 1997; Józsa \& Kannus, 1997a; Józsa \& Kannus, 1997b; Benjamin, 2004).

Tendon is a dense fibrous connective tissue, consisting of relatively few fibroblasts (tenocytes) embedded in a collagen-rich matrix. Haematoxylin and eosin (H\&E) preparations of human Achilles tendon show the highly organized collagen fibril bundles running longitudinally through the matrix and the elongated tenocyte nuclei squeezed between them (See Fig. 1a). The cells are generally widely dispersed, although they have been shown to communicate with each other via gap junctions at the end of long cellular processes, both longitudinally and laterally throughout the tendon (McNeilly et al., 1996).

A typical feature of painful Achilles tendinopathy, shared with other tendon lesions at various sites, is an infiltration of blood vessels and increased cellularity, a so-called "angiofibroblastic" response
(Leadbetter, 1992; Jarvinen et al., 1997) (See Fig. 1b). The majority of cells at the site of the lesion are fibroblasts, often rounded or ovoid, and there is rarely any evidence of inflammatory cells within the tendon, or in the surrounding paratenon (Åström \& Rausing, 1995). The proteoglycan content is increased compared with normal tendon, as shown by toluidine blue staining of the matrix (Fig 1c and d). These degenerative changes are thus thought to represent an active, cell-mediated process that results in substantial changes to the structure and composition of the tendon matrix.

\section{The biochemistry of tendinopathy}

Several studies have addressed the major biochemical changes in tendon matrix composition in human tendinopathy (Riley et al., 1994a, b, 1996a, b, 2002; Bank et al., 1999; Ireland et al., 2001). Predominantly consisting of collagen, there are many other matrix constituents, including proteoglycans and noncollagen glycoproteins, many of which are poorly characterized (Aumailley \& Gayraud, 1998). For example, there are 27 different collagen molecules now identified, although little is known about the tissue distribution and function of the less abundant "minor" collagens, particularly types XX to XXVII which were discovered relatively recently (Fitzgerald \& Bateman, 2001; Koch et al., 2001; Hashimoto et al., 2002; Sato et al., 2002; Banyard et al., 2003; Boot-Handford et al., 2003; Koch et al., 2003; Pace et al., 2003; Myllyharju \& Kivirikko, 2004).

A normal tendon contains mostly type I collagen, estimated to represent almost $95 \%$ of the total collagen, with smaller amounts of collagen types

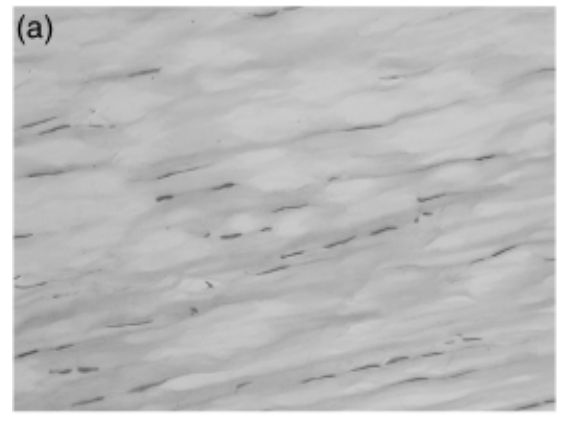

(c)
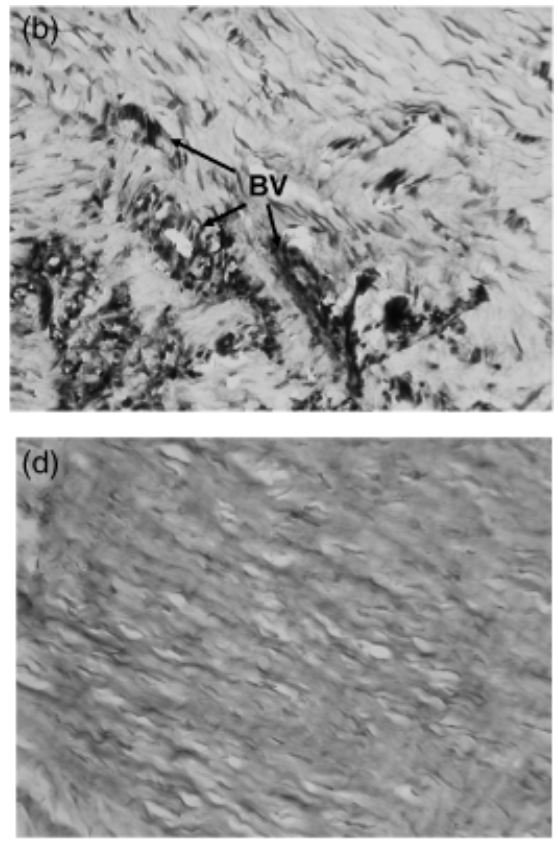

Fig. 1. Histopathology of tendinopathy. Normal Achilles tendon from a cadaver (a, c) and a surgical specimen from a patient with tendinopathy $(b$, d) were fixed, frozen and prepared for standard histology. (a) and (b) were stained with haemotoxylin and eosin, (c) and (d) were stained with toluidine blue to show matrix proteoglycans/ glycosaminoglycans. (a) Normal tendon histology, with long thin fibroblasts dispersed in the ordered fibrillar matrix. (b) Blood vessel (BV) infiltration and cellular proliferation within the degenerate tendon lesion, with no inflammatory cells visible. (c) Relative absence of proteoglycans in the normal tendon matrix. (d) A substantial increase in proteoglycan throughout the degenerate tendon matrix. 
III, V, VI, XII and XIV, at levels which are difficult to quantitate by current methodologies (Riley, 2004b). In addition, collagen types II, IX, X and $\mathrm{XI}$ are present at specific sites of "fibrocartilage, found at the bone insertion and where the tendon is subject to shear forces or compression (Fukuta et al., 1998; Waggett et al., 1998). These "minor" collagens, although a very small proportion of the total, are implicated in a number of important processes including collagen fibril formation, regulating the ultimate diameter of the fibrils and mediating interactions with the surrounding cells and matrix (Aumailley \& Gayraud, 1998).

Most is known about the major fibrillar collagens of tendon, types I and III, since these are more amenable to analysis, most abundant and more readily extracted from the tissue, which becomes increasingly insoluble with age (Riley et al., 1994a). We have previously shown that degenerate tendons, such as the supraspinatus in the shoulder, have a small but significant reduction in the total collagen content relative to the tissue dry weight (Riley et al., 1994a). This was partly because of an increase in the non-collagen glycoprotein content, as well as increases in matrix proteoglycan (Riley et al., 1994b). The type and distribution of collagen also changed, with an increase in the proportion of type III collagen and a corresponding decrease in the concentration of type I collagen (Riley et al., 1994a). The type III collagen was found associated with the type I collagen fibril bundles by immunohistochemistry, thought to be intercalated into the fibrils, suggesting that the original fibrils had been extensively remodelled, resulting in a greater proportion of small diameter and randomly organized fibrils. The collagen was more readily extracted from degenerate tendon, although the level of mature collagen crosslinks was elevated compared with normal (Bank et al., 1999). Thus it appeared that the newly synthesized collagen had been resident in the tissues at least long enough for the maturation of collagen crosslinks, after whatever stimulus had driven the change in collagen synthesis.

The levels of the glycation cross-link, pentosidine, a marker of the molecular age of the matrix, was also lower than expected for the age of the individual, confirming that much of the original fiber network had been replaced by new collagen (Bank et al., 1999). This finding was confirmed by analysis of the racemization of aspartate, another marker of protein residence time (Riley et al., 2002). Macroscopically normal supraspinatus tendons showed relatively high levels of matrix turnover compared with normal biceps brachii tendons (which showed very little if any matrix turnover), although less than degenerate supraspinatus. These data are consistent with the hypothesis that increased matrix turnover is associated with the sub-clinical matrix degeneration that precedes the clinical condition. Similar biochemical evidence now exists for the Achilles, suggesting that remodelling of the tendon is a general feature of tendinopathy (Eriksen et al., 2002). Whether this remodelling weakens the tendon is a moot point, since many cases of painful tendinopathy persist for months if not years, and do not go on to rupture.

Very little is known about the changes in proteoglycan in tendinopathy, apart from the generalized increase in sulfated glycosaminoglycan, the majority of which was chondroitin sulfate (Riley et al., 1994b). There are several proteoglycan species in tendon, including the large hyalectans, aggrecan and versican, and the small leucine-rich proteoglycans (SLRP), decorin, biglycan, fibromodulin and lumican (Berenson et al., 1996; Waggett et al., 1998). Versican is thought to be the major hyalectan in the tendon mid-substance and aggrecan is more abundant in fibrocartilage. Of the SLRPs, decorin is the most abundant and the biglycan content is increased in fibrocartilaginous regions. Thus the proteoglycan content is an indicator of the "mechanical history" of tendon, with regions exposed to predominantly tensile load rich in versican and decorin, and regions that are compressed or subject to shear forces (such as the insertion) are rich in aggrecan and biglycan. The proteoglycans turn over much more rapidly than fibrillar collagen, as part of the normal tissue maintenance, although hyalectans have a greater rate of turnover than the SLRP (Rees et al., 2000; Samiric et al., 2004a, b). Apart from acting to hold water in the tissues, the proteoglycans have roles in the resistance of compression, lubricating movement of adjacent fiber bundles, mediating cell-matrix interactions and the sequestration of growth factors and enzymes in the matrix (Hardingham \& Fosang, 1992). It is uncertain what role, if any, fibrocartilage plays in tendinopathy, although pathology is frequently found in fibrocartilaginous regions of tendon, which are avascular and therefore potentially less capable of repair. For example, it has been postulated that fibrocartilage may develop in tendon in response to excessive shear or compressive forces, and may be a precursor of pathology (Cawston et al., 1996). On the other hand, fibrocartilage formation may be part of the normal adaptive process, which functions to protect tendon against potentially harmful patterns of loading (Vogel \& Koob, 1989).

Non-collagen glycoproteins in tendon include tenascin-C, cartilage oligomeric matrix protein (COMP), fibronectin, elastin, fibrillin, laminin and link protein (Józsa \& Kannus, 1997a; Kannus, 2000; Riley, 2004b). Again, relatively little is known about changes in glycoprotein content in tendinopathy. Fibronectin and tenascin-C are up-regulated after injury, and are thought to play a role in modulating 
cell migration and activity (Mackie et al., 1988; Lehto et al., 1990; Amiel et al., 1991). There are changes in the expression of tenascin- $\mathrm{C}$ in chronic tendinopathy, with changes in the splice variants expressed as well as increased abundance, predominantly associated with rounded cells in the degenerate matrix (Riley et al., 1996b).

In summary, the biochemical changes in tendinopathy are still relatively poorly characterized, although the evidence to date is consistent with the hypothesis that accumulated "micro-trauma" affect the cellular expression of many different matrix components. The question remains whether this represents a response to injury (i.e. damage to the matrix structure) or modulation of the tenocyte activity by mechanical strain, directly affecting the turnover of tendon matrix components.

\section{Adaptation of tendon and the response to mechanical load}

Studies with animals have shown that changes in matrix quantity and quality can be induced by altering the mechanical strain experienced by the tendon (Gillard et al., 1979; Woo et al., 1981, 1982; Tipton et al., 1986; Akeson et al., 1987; Curwin et al., 1988; Hannafin, 1995; Yasuda \& Hayashi, 1999). The most dramatic changes can be induced by immobilization or stress-shielding, resulting in a fairly rapid loss of tendon strength and a reduction in the matrix (collagen) mass (Tipton et al., 1986; Akeson et al., 1987; Yasuda \& Hayashi, 1999). There is a reduction in the total area of collagen fibrils in the tendon cross-section, and an increased number of thin and immature fibrils (Yasuda \& Hayashi, 1999). The changes in tensile properties were dependent on the presence of a viable cell population, and could be reversed by the application of cyclic tensile loading in vitro (Hannafin, 1995). Similar results were reported for in vivo studies, with the tendon slowly returning to normal after the resumption of loading, although the insertion responds more slowly compared with the mid-substance (Woo et al., 1987). Mechanical load is important for improving the strength of healing tendon after injury (Gelberman et al., 1981), although the response of normal tendon to exercise is more equivocal. Small increases in the material properties of exercised tendons have been reported, although these were studies of relatively immature animals, and may not reflect the situation in adult tendon (Woo et al., 1981, 1982; Curwin et al., 1988). Indeed, studies of equine tendons have suggested that exercise may have only a deleterious effect on the adult tendon matrix, and only immature tendons are capable of an adaptive response (Patterson-Kane et al., 1997; Smith et al., 1999; Smith et al.,
2002). However, studies of human tendon using dialysis catheters placed adjacent to the tendon have shown that acute exercise in healthy volunteers will stimulate collagen synthetic activity, in addition to increasing tendon blood flow, metabolic activity and the release of certain inflammatory mediators and matrix-degrading matrix metalloproteinases (MMP) (Langberg et al., 1998, 1999, 2001; Kjaer et al., 2000; Heinemeier et al., 2003; Koskinen et al., 2004). Since isolated tendon cells can be stimulated to produce interleukin (IL)-1 $\beta$, cyclooxygenase 2 (COX 2) and MMP (MMP-1 and MMP-3) by mechanical load and fluid-induced shear stress in vitro, an affect that may be modulated by negative feedback from extracellular ATP, this provides a theoretical basis for the induction of tendinopathy by repeated cyclical loading below the injury threshold (Archambault et al., 2002; Tsuzaki et al., 2003a).

\section{Mediators of matrix degradation - the MMPs}

Proteolytic activity is an essential component of tissue growth, maintenance, adaptation and repair. After injury, proteolysis is required to remove any damaged matrix and remodel the newly formed scar so that it more closely resembles the normal tissue. Some collagen in tendon is probably degraded intracellularly after phagocytosis, with fibroblasts and macrophages engulfing collagen molecules which are then digested by lysosomal enzymes (Everts et al., 1996; Creemers et al., 1998). This is a major activity in the rapidly remodelling peridontal ligament, although few studies have investigated the relative importance of this route in tendon. Most studies have focused on collagen degradation occurring in the extracellular environment and mediated by secreted enzymes known as MMP.

Comprehensive reviews of the MMP have been published elsewhere and only salient points are reviewed here (Matrisian, 1990; Murphy et al., 1994; Nagase, 1994; Birkedal-Hansen, 1995; Cawston, 1995; McCawley \& Matrisian, 2001; Clark \& Parker, 2003). MMP are members of the "MB" clan of metallopeptidases, generically referred to as "metzincins" since they contain zinc at the active site and a conserved methionine eight residues downstream. They possess activity at neutral $\mathrm{pH}$ against a broad spectrum of different matrix substrates. Although important in matrix degradation, MMP also have activity against cell surface receptors and growth factor precursors (McCawley \& Matrisian, 2001). Consequently these enzymes also have an important role in the regulation of numerous cellular activities including cell proliferation, cell death (apoptosis), cell migration and chemotaxis (McCawley \& Matrisian, 2001). 
There are 23 MMPs found in human, which can be subdivided into collagenases, gelatinases, stromelysins and membrane-type MMP, based on their structures and substrate specificities (Nagase, 1994; Cawston, 1995; Clark \& Parker, 2003) (See Fig. 2). Collagenases are some of the few enzymes capable of cleaving the intact type I collagen molecule in the extracellular environment, which occurs at a specific locus in the triple helix between residues 775 and 776 (Cawston, 1995). The initial cleavage by a collagenase is the rate-limiting step in fibrillar collagen turnover, generating $\frac{3}{4}$ and $\frac{1}{4}$ length fragments that are susceptible to other enzymes such as the gelatinases. MMPs with collagenase activity include MMP-1 (collagenase-1; EC 3.4.24.7), MMP-8 (neutrophil collagenase; EC 3.4.24.34), MMP-13 (collagenase-3; MEROPS ID M10.013), MMP-2 (gelatinase A; EC 3.4.24.24) and MMP-14 (MT1-MMP; MEROPS ID M10.014). The collagenases differ in their activities against the various fibrillar collagens, although precisely which enzymes are implicated in the physiological and pathological turnover of connective tissues such as tendon is still the subject of research.

The activities of MMPs are normally tightly controlled in vivo, with regulation at the levels of transcription, translation, activation and inhibition. In general, expression and activity of the MMPs is stimulated by pro-inflammatory cytokines such as IL-1 and tumour necrosis factor (TNF), and inhibited by growth factors such as transforming growth factor- $\beta$ (TGF- $\beta$ ). MMPs are potently inhibited by $\alpha$ 2 macroglobulin in the serum, and also by a family of

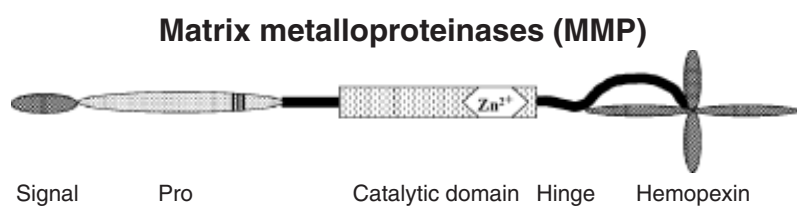
A family of 23 enzymes
$>$ Collagenases: MMP-1, $-8,-13$
$>$ Gelatinases: MMP-2, -9
$>$ Stromelysins: MMP-3,-10
$>$ Membrane-type MMPs: MMP-14, -15, -16, -17, -24
Regulated at various levels
$>$ Synthesised as inactive pro-enzyme
$>$ Activated by other proteinases
> Inhibited by TIMP (TIMP-1, TIMP-2, TIMP-3, TIMP-4)

Fig. 2. The matrix metalloproteinase family. Diagram of the general domain structure of matrix metalloproteinases (MMP). Most MMP are synthesized with a pro-domain, which is enzymatically removed to activate the enzyme. The catalytic domain contains zinc at the active site. The hemopexin domain is essential for the substrate specificity of collagenases. There are variations in structure between the different family numbers, some of which lack the hemopexin domain and others also possess a trans-membrane domain. specific inhibitors produced by cells within the tissues known as tissue inhibitors of metalloproteinases (TIMPs) (Murphy et al., 1994; Cawston, 1995; Murphy \& Willenbrock, 1995). There are four TIMPs that have been characterized to date, and these may be constitutively expressed, such as TIMP2 , or stimulated by growth factors such as TGF- $\beta$, such as TIMP-1 and TIMP-3. Each TIMP will bind to active MMPs in a stoichiometric (1:1) ratio, resulting in a stable, inactive complex.

\section{Mediators of matrix proteoglycan degradation - the "aggrecanases"}

Proteoglycans are turned over much more rapidly than the fibrillar collagens (Birkedal-Hansen, 1995; Cawston, 1995). Although some members of the MMP family such as MMP-3 (stromelysin-1) can degrade proteoglycans such as aggrecan in vitro, most activity in vivo is associated with a related but distinct group of metallo-endopeptidases, commonly known as "aggrecanases".

Aggrecanases were first identified on the basis of their ability to cleave aggrecan at specific Glu-Xaa bonds, with a major site in the interglobular (IGD) domain of the aggrecan core protein $\left(\mathrm{Glu}^{373}-\mathrm{Ala}^{374}\right)$, resulting in the loss of the glycosaminoglycan-rich portion of the molecule from the tissue (Sandy et al., 1991). This activity was associated with the loss of cartilage proteoglycan that accompanies osteoarthritis (Sandy et al., 1992). Aggrecanases were subsequently identified as members of the a disintegrin and metalloproteinase (ADAM)-thrombospondin (TS) family, a sub-group of ADAM with TS type I motifs (Kaushal \& Shah, 2000; Cal et al., 2002).

To date, 19 mammalian ADAMTS enzymes have been identified, many of which remain to be fully characterized (Kaushal \& Shah, 2000; Cal et al., 2002) (See Fig. 3). ADAMTS-2, ADAMTS-3 and ADAMTS-14 are pro-collagen peptidases, and function as key regulators of collagen fibril assembly (Colige et al., 1999; Fernandes et al., 2001; Colige et al., 2002). ADAM-TS4 (aggrecanase 1) and ADAM-TS5 (aggrecanase 2) were the first aggrecanases to be identified (Abbaszade et al., 1999; Tortorella et al., 1999; Kaushal \& Shah, 2000) although activity has since been also attributed to the phylogenetically related enzymes ADAMTS-1, ADAMTS8, ADAMTS-9 and ADAMTS-15 (Kuno et al., 2000; Yamaji et al., 2000; Somerville et al., 2003; CollinsRacie et al., 2004). Best known for their activity against aggrecan, ADAMTS1 and ADAMTS-4 are also capable of cleaving other matrix proteoglycans such as versican and brevican (Sandy et al., 2001), and glycoproteins such as COMP (Dickinson et al., 2003), at least in vitro. Although inhibition of 


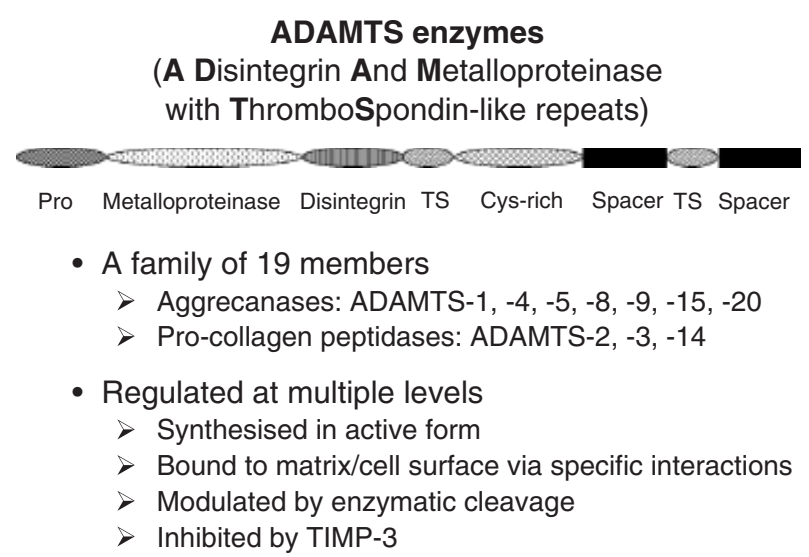

Fig. 3. The ADAMTS family of enzymes. Diagram of the general domain structure of the ADAMTS enzymes. Several members of the family are able to cleave proteoglycans such as aggrecan and versican and are given the generic title "aggrecanases". Other members of the family are procollagen peptidases, involved in the processing of collagen molecules prior to the formation of fibrils. The functions of the remaining family members are currently poorly understood.

ADAMTS- 4 and -5 can prevent cartilage degradation in tissue culture models (Tortorella et al., 2001), the enzymes responsible for proteoglycan degradation in osteoarthritis and other diseases of connective tissues have yet to be identified.

Aggrecanase activity is thought to be regulated at multiple levels, although the mechanisms are currently poorly understood. Differential regulation of ADAMTS mRNA has been deduced from analysis of their expression in cell and explant cultures, albeit with considerable variation between studies (Caterson et al., 1999; Tortorella et al., 2001; Vankemmelbeke et al., 2001; Koshy et al., 2002; Tsuzaki et al., 2003b). A study of human tendon cells recently reported small and variable effects of IL-1 on ADAMTS-4 expression (Tsuzaki et al., 2003b).

In addition to regulation of gene transcription, the activities of ADAMTS enzymes are also subject to post-translational regulation. The non-catalytic ancillary domains of ADAMTS-4 are required for both catalytic activity and substrate specificity (Flannery et al., 2002; Kashiwagi et al., 2003). Full-length enzyme is sequestered in the matrix via GAG-binding sequences in the spacer domain, and sulfated GAGs attached to the aggrecan core protein are required for ADAMTS-4 activity (Kashiwagi et al., 2003). Deletion of the C-terminal spacer domain increased the efficiency of hydrolysis of aggrecan at $\mathrm{Glu}^{373}-\mathrm{Ala}^{374}$ bonds, and revealed new activities against fibromodulin, decorin and a general protein substrate (Kashiwagi et al., 2003). Several short forms of ADAMTS-4 are found in cartilage, thought to be generated by autocatalytic C-terminal truncation, potentially contributing to the degradation of a broad range of protein substrates in addition to PGs (Flannery et al., 2002; Kashiwagi et al., 2003). The enzymes are thought to be secreted in an active form after cleavage of the pro-domain within the cell by furin, which may be followed by C-terminal truncation by MMP-17 at the cell surface (Gao et al., 2003; Wang et al., 2004). Active ADAMTS are inhibited by the endogenous inhibitor TIMP-3, but not by other TIMPs (Kashiwagi et al., 2001).

\section{Matrix degradation in tendinopathy}

Several MMP have been implicated in matrix degradation of tendon. Specimens of human rotator cuff tendons placed in culture were shown to synthesize collagenase (MMP-1) and TIMP-1, and there was no significant difference between normal and degenerate tendons (Dalton et al., 1995). Thus degenerate tendons were shown to be capable of remodelling the tendon matrix, even at a late stage of the disease, although the factors regulating this activity in vivo were not identified (Dalton et al., 1995). A comparison of human tendons showed substantial differences in collagen turnover between tendons from different sites. There was very little collagen turnover in normal biceps brachii tendons, which contained no significant levels of metalloproteinase activity and the linear accumulation of pentosidine with increasing age (Riley et al., 2002). In contrast, supraspinatus tendons obtained from normal shoulders showed relatively high levels of collagen turnover, with lower levels of pentosidine than expected for the age of the tissue, and there were correspondingly high levels of MMP-1, MMP-2 and MMP-3 activity (Riley et al., 2002). These enzyme activities were thought to represent either a repair or maintenance function, occurring in the normal supraspinatus as a result of the high mechanical demands placed upon the tendon in the shoulder. It may also be associated with an underlying degenerative process, which was common in asymptomatic shoulders, potentially caused by repeated minor injuries, mechanical strain or "overuse". In ruptured supraspinatus tendon there was increased activity of MMP-1, reduced activity of MMP-2 and MMP-3, and evidence of increased turnover of the collagen network (Riley et al., 2002). The potential role of MMPs in (or after) tendon rupture was also demonstrated by a study of synovial fluids from patients with rotator cuff tears. There were high levels of expression of both MMP-1 and MMP-3, with no change in the levels of TIMP-1, and the levels of enzyme correlated with the size of tear (Yoshihara et al., 2001). Glycosaminoglycan levels were also higher in fluids from massive tears compared with partial tears, consistent with increased turnover of matrix proteoglycans 
(Yoshihara et al., 2001). Immunolocalization of ruptured supraspinatus showed MMP-1 expressed in the tendon at the edge of the tear (Gotoh et al., 1997). Tendon degeneration was thus shown to be an active, cell-mediated process that may result from a failure to regulate specific MMP activities in response to repeated injury or mechanical strain. It is most likely to be mediated by the resident tenocyte population, although some contribution from surrounding tissues and infiltrating cells cannot be definitively excluded in pathological situations. It has also been demonstrated that matrix turnover is substantially higher in tendons exposed to high mechanical demands (Riley et al., 2002), and this is thought to represent either a repair or maintenance function.

Relatively little is currently known about proteoglycan turnover in tendinopathy. Since levels of proteoglycan are increased in the degenerate tendon lesion (unlike degenerate cartilage) it will be interesting to determine whether this is caused by an increase in proteoglycan synthesis or a decrease in proteoglycan degradation mediated by aggrecanases (or both). These studies are currently hampered by the limited availability of sensitive and specific aggrecanase activity assays, although technical developments in this area are expected soon.

\section{Gene expression in tendinopathy}

Analysis of gene expression in human tendon specimens has not been widely attempted, although techniques of molecular biology such as cDNA arrays and real time reverse transcriptase-polymerase chain reaction (RT-PCR) are capable of providing at least a semi-quantitative analysis of many different gene targets in very small tissue samples, such as can be obtained from tendon biopsies. These techniques are highly sensitive, specific and can provide useful information about cell activities in the tissue.

There are two published studies describing the use of cDNA arrays to investigate gene expression in Achilles tendinopathy (Ireland et al., 2001; Alfredson et al., 2003). A number of genes were found to show either increased or decreased expression in degenerate tendon, however in several cases apparent changes in gene expression were not confirmed by RT-PCR analysis of a greater number of tissue specimens (Alfredson et al., 2003; Corps et al., 2004). This serves to highlight inherent drawbacks of the technique, which requires relatively large amounts of RNA and is expensive, and is often used to compare a relatively small number of specimens.

Recently, we have investigated the expression of several matrix and enzyme genes in human Achilles tendon specimens using real time semi-quantitative
RT-PCR. We obtained macroscopically normal tendons $(n=14)$ from cadavers and tissue specimens obtained during surgery. The surgical specimens were either from patients with a history of chronic pain $(n=10)$, or had suffered an acute tendon rupture $(n=8)$. All specimens were obtained after informed consent and with the approval of the Cambridge Local Research Ethical Committee. RTPCR analysis of two collagen genes (COL1A1 and COL3A1) showed relatively high but variable levels of expression in normal tendon, and significantly increased expression of both genes in painful tendinopathy (Riley GP, unpublished observations). These findings are consistent with biochemical analyses, which showed changes in collagen synthesis prior to tendon rupture (Eriksen et al., 2002). An analysis of versican mRNA, the major hyalectan found in tendon (see above), showed that two splice variants (V0 and V1) were most abundant, and there was a significant decrease in versican mRNA in both painful and ruptured tendons (Corps et al., 2004). Of the MMP genes that have been investigated to date, there was little detectable expression of MMP-1 and MMP-13 in any of the specimens, whether normal or degenerate (Riley GP, unpublished observations). Since both these collagenases are stimulated by inflammatory cytokines, this observation is consistent with the non-inflammatory nature of the lesion. There was a small but significant reduction in MMP2 mRNA, but the most dramatic change was in the level of MMP-3 mRNA, which was substantially lower in painful and ruptured tendons. This study confirmed earlier observations made using cDNA arrays and biochemical analysis, which suggested that MMP-3 was potentially important for the maintenance of the normal tendon matrix (Ireland et al., 2001). However the substrate for MMP-3 in tendon has not been identified, and since most of the enzyme is in the inactive pro-form, the physiological relevance is uncertain. Finally, an analysis of the expression of three aggrecanases, ADAMTS-1, ADAMTS4 and ADAMTS-5, showed expression of all three enzymes in the tissue specimens (Riley GP, unpublished observations). When expressed relative to the housekeeping gene GAPDH, there was found to be no significant change in ADAMTS-4, although ADAMTS- 1 was reduced in ruptured tendon and ADAMTS-5 was reduced in both painful and ruptured tendons (unpublished). These observations require confirmation and their potential significance is uncertain, but it is possible to speculate that a reduction in aggrecanase expression may underlie the increase in proteoglycan found in degenerate tendon.

There are several caveats that must be taken into consideration in any study of gene expression in surgical and post-mortem tissues. Levels of gene expression may not correlate with levels of protein 
expression or enzyme activity. This is particularly relevant with respect to the MMP, which are regulated at multiple levels and not just at the level of synthesis. The analysis of small biopsies may not be representative of the whole tendon, which generally shows highly focal changes in cellularity and matrix organization. The specimens are homogenized, and expression may be localized at specific sites within the tendon. The tendon specimens were also obtained from a heterogeneous group of patients, varying widely in several parameters such as age, levels of physical activity and the duration of disease. The analysis also provides only a "snap-shot" of cell activity, representing only the time of sampling, and changes in gene expression may be relatively transient. Finally, surgery, drug treatment, tissue storage and post-mortem changes can all profoundly affect the levels of expression in the tissue specimens, as well as reduce the quality of mRNA. With these caveats in mind, analyses of gene expression are able to provide some insight into the metabolic activity of human tendon, and will provide an important adjunct to biochemical techniques.

\section{Perspectives}

The evidence presented suggests that tenocytes are actively synthesizing and degrading the matrix in normal tendon, and that these activities are substantially altered in tendinopathy. Some matrix turnover is beneficial for the health of the tendon, a contention that is supported by the observation that drugs which affect the expression or activity of MMP, such as broad-spectrum MMP inhibitors and fluoroquinolone antibiotics, can induce tendon lesions in patients being treated for other conditions (Pierfitte \& Royer, 1996; Brown, 1999; Corps et al., 2002). A large number of enzymes are potentially implicated in this process, since there are at least 23 MMPs and 19 ADAMTS enzymes, and studies to date have focused on relatively few of these. Some of these enzymes are likely to be required for normal tendon maintenance or repair, whilst others may be damaging to the tendon and responsible for matrix degeneration. Consequently it is important that the complete profile of enzyme expression and activity in human tendon is characterized, so that specific targets for future drug therapy can be identified.

Key words: matrix metalloproteinase, MMP, aggrecanase, ADAMTS.

\section{Acknowledgements}

The author would like to acknowledge financial support from the Arthritis Research Campaign, The Isaac Newton Trust, REMEDI, The Wishbone Trust, The Dunhill Medical Trust, The Sybil Eastwood Trust and the Cambridge Arthritis Research Endeavour (CARE). Thanks are also due to past and present members of the Rheumatology Research Unit, especially Dr. Brian Hazleman, Professor Tim Cawston, Dr. Ian Clark, Dr. David Buttle, Dr. Steven Fenwick and Dr. Anthony Corps.

\section{References}

Abbaszade I, Liu RQ, Yang F, Rosenfeld SA, Ross OH, Link JR, Ellis DM, Tortorella MD, Pratta MA, Hollis JM, Wynn R, Duke JL, George HJ, Hillman MC Jr., Murphy K, Wiswall BH, Copeland RA, Decicco CP, Bruckner R, Nagase H, Itoh Y, Newton RC, Magolda RL, Trzaskos JM, Burn TC. Cloning and characterization of ADAMTS11, an aggrecanase from the ADAMTS family. J Biol Chem 1999: 274(33): 23443-23450.

Akeson WH, Amiel D, Abel MF, Garfin SR, Woo SL. Effects of immobilization on joints. Clin Orthop 1987: 219: 28-37.

Alfredson $\mathrm{H}$, Lorentzon M, Backman S, Backman A, Lerner UH. CDNA-arrays and real-time quantitative PCR techniques in the investigation of chronic achilles tendinosis. J Orthop Res 2003: 21(6): 970-975.

Amiel D, Gelberman RH, Harwood F, Siegel D. Fibronectin in healing flexor tendons subjected to immobilization or early controlled passive motion. Matrix 1991: 11: 184-189.
Archambault J, Tsuzaki M, Herzog W, Banes AJ. Stretch and interleukin-1beta induce matrix metalloproteinases in rabbit tendon cells in vitro. J Orthop Res 2002: 20(1): 36-39.

Åström M, Rausing A. Chronic achilles tendinopathy. A survey of surgical and histopathologic findings. Clin Orthop 1995: 316: 151-164.

Aumailley M, Gayraud B. Structure and biological activity of the extracellular matrix. J Mol Med 1998: 76: 253-265.

Bank RA, TeKoppele JM, Oostingh G, Hazleman BL, Riley GP. Lysylhydroxylation and non-reducible cross-linking of human supraspinatus tendon collagen: changes with age and in chronic rotator cuff tendinitis. Ann Rheum Dis 1999: 58: 35-41.

Banyard J, Bao L, Zetter BR. Type XXIII collagen, a new transmembrane collagen identified in metastatic tumor cells. J Biol Chem 2003: 278(23): 20989-20994.

Benjamin M. The structure and function of tendons. In: Hazleman BL, Riley
GP, Speed CA. Soft tissue rheumatology. Oxford: Oxford University Press, 2004: 9-19.

Berenson MC, Blevins FT, Plaas AHK, Vogel KG. Proteoglycans of human rotator cuff tendons. J Orthop Res 1996: 14: 518-525.

Birkedal-Hansen H. Proteolytic remodeling of extracellular matrix. Curr Opin Cell Biol 1995: 7: 728-735.

Boot-Handford RP, Tuckwell DS, Plumb DA, Rock CF, Poulsom R. A novel and highly conserved collagen (Pro(Alpha)1(XXVII)) with a unique expression pattern and unusual molecular characteristics establishes a new clade within the vertebrate fibrillar collagen family. J Biol Chem 2003: 278(33): 31067-31077.

Brown PD. Clinical studies with matrix metalloproteinase inhibitors. Apmis 1999: 107(1): 174-180.

Cal S, Obaya AJ, Llamazares M, Garabaya C, Quesada V, Lopez-Otin C. Cloning, expression analysis, and structural characterization of seven 
novel human ADAMTSs, a family of metalloproteinases with disintegrin and thrombospondin-1 domains. Gene 2002: 283(1-2): 49-62.

Caterson B, Flannery CR, Hughes CE, Little CB. Mechanisms of proteoglycan metabolism that lead to cartilage destruction in the pathogenesis of arthritis. Drugs Today (Barc.) 1999: 35(4-5): 397-402.

Cawston TE. Proteinases and inhibitors. Br Med Bull 1995: 51: 385-401.

Cawston TE, Riley GP, Hazleman BL. Tendon lesions and soft tissue rheumatism - great outback or great opportunity. Ann Rheum Dis 1996: 55: $1-3$.

Clark IM, Parker AE. Metalloproteinases: their role in arthritis and potential as therapeutic targets. Expert Opin Ther Targets 2003: 7(1): 19-34.

Colige A, Sieron AL, Li SW, Schwarze U, Petty E, Wertelecki W, Wilcox W, Krakow D, Cohn DH, Reardon W, Byers PH, Lapiere CM, Prockop DJ, Nusgens BV. Human Ehlers-Danlos syndrome type VII C and bovine dermatosparaxis are caused by mutations in the procollagen I Nproteinase gene. Am J Hum Genet 1999: 65(2): 308-317.

Colige A, Vandenberghe I, Thiry M, Lambert CA, Van Beeumen J, Li SW, Prockop DJ, Lapiere CM, Nusgens BV. Cloning and characterization of ADAMTS-14, a novel ADAMTS displaying high homology with ADAMTS-2 and ADAMTS-3. J Biol Chem 2002: 277(8): 5756-5766.

Collins-Racie LA, Flannery CR, Zeng W, Corcoran C, Annis-Freeman B, Agostino MJ, Arai M, DiBlasio-Smith E, Dorner AJ, Georgiadis KE, Jin M, Tan XY, Morris EA, LaVallie ER. ADAMTS-8 exhibits aggrecanase activity and is expressed in human articular cartilage. Matrix Biol 2004: 23(4): 219-230.

Corps AN, Harrall RL, Curry VA, Fenwick SA, Hazleman BL, Riley GP. Ciprofloxacin enhances the stimulation of matrix metalloproteinase 3 expression by interleukin-1beta in human tendon-derived cells. A potential mechanism of fluoroquinolone-induced tendinopathy. Arthritis Rheum 2002: 46: 3034-3040.

Corps AN, Robinson AH, Movin T, Costa ML, Ireland DC, Hazleman BL, Riley GP. Versican splice variant messenger RNA expression in normal human achilles tendon and tendinopathies. Rheumatology 2004: 43: 969-972.

Creemers LB, Jansen IDC, Docherty AJP, Reynolds JJ, Beertsen W, Everts V. Gelatinase A (MMP-2) and cysteine proteinases are essential for the degradation of collagen in soft connective tissue. Matrix Biol 1998: 17: 35-46.

Curwin SL, Vailas AC, Wood J. Immature tendon adaptation to strenuous exercise. J Appl Physiol 1988: 65: 2297-2301.

Dalton S, Cawston TE, Riley GP, Bayley IJL, Hazleman BL. Human shoulder tendon biopsy samples in organ culture produce procollagenase and tissue inhibitor of metalloproteinases. Ann Rheum Dis 1995: 54: 571-577.

Dickinson SC, Vankemmelbeke MN, Buttle DJ, Rosenberg K, Heinegard D, Hollander AP. Cleavage of cartilage oligomeric matrix protein (thrombospondin-5) by matrix metalloproteinases and a disintegrin and metalloproteinase with thrombospondin motifs. Matrix Biol 2003: 22(3): 267-278.

Eriksen HA, Pajala A, Leppilahti J, Risteli J. Increased content of type III collagen at the rupture site of human achilles tendon. J Orthop Res 2002: 20(6): 1352-1357.

Everts V, Van der Zee E, Creemers L, Beertsen W. Phagocytosis and intracellular digestion of collagen, its role in turnover and remodelling. Histochem J 1996: 28: 229-245.

Fernandes RJ, Hirohata S, Engle JM, Colige A, Cohn DH, Eyre DR, Apte SS. Procollagen II amino propeptide processing by ADAMTS-3. Insights on dermatosparaxis. J Biol Chem 2001: 276(34): 31502-31509.

Fitzgerald J, Bateman JF. A new FACIT of the collagen family: COL21A1. FEBS Lett 2001: 505(2): 275-280.

Flannery CR, Zeng W, Corcoran C, Collins-Racie LA, Chockalingam PS, Hebert T, Mackie SA, McDonagh T, Crawford TK, Tomkinson KN, LaVallie ER, Morris EA. Autocatalytic cleavage of ADAMTS-4 (aggrecanase1) reveals multiple glycosaminoglycanbinding sites. J Biol Chem 2002: 277(45): 42775-42780.

Fukuta S, Oyama M, Kavalkovich K, Fu FH, Niyibizi C. Identification of types II, IX and X collagens at the insertion site of the bovine achilles tendon. Matrix Biol 1998: 17: 65-73.

Gao G, Plaas AH, Thompson VP, Jin S, Zuo F, Sandy JD. ADAMTS4 (aggrecanase-1) activation on the cell surface involves $\mathrm{C}$-terminal cleavage by GPI-anchored MT4-MMP and binding of the activated proteinase to chondroitin sulfate and heparan sulfate on syndecan-1. J Biol Chem 2004: 279(11): 10042-10051.

Gelberman RH, Amiel D, Gonsalves M, Woo SLY, Akeson WH. The influence of protected passive mobilization on the healing of flexor tendons: a biochemical and microangiographic study. Hand 1981: 13(2): 120-128.

Gillard GC, Reilly HC, Bell-Booth PG, Flint MH. The influence of mechanical forces on the glycosaminoglycan content of the rabbit flexor digitorum profundus tendon. Conn Tiss Res 1979: 7: $37-46$

Gotoh M, Hamada K, Yamakawa H, Tomonaga A, Inoue A, Fukuda HO. Significance of granulation tissue in torn supraspinatus insertions: an immunohistochemical study with antibodies against interleukin-1b, cathepsin D, and matrix

metalloprotease- 1. J Orthop Res 1997: 15: 33-39.

Hannafin JA. Effect of stress deprivation and cyclic tensile loading on the material and morphologic properties of canine flexor digitorum profundus tendon: an in vitro study. J Orthop Res 1995: 13: 907-914.

Hardingham TE, Fosang AJ. Proteoglycans: many forms and many functions. FASEB J 1992: 6: 861-870.

Hashimoto T, Wakabayashi T, Watanabe A, Kowa H, Hosoda R, Nakamura A, Kanazawa I, Arai T, Takio K, Mann DM, Iwatsubo T. CLAC: a Novel Alzheimer amyloid plaque component derived from a transmembrane precursor, CLAC-P/collagen type XXV. EMBO J 2002: 21(7): 1524-1534.

Heinemeier K, Langberg H, Olesen JL, Kjaer M. Role of TGF-beta1 in relation to exercise-induced type I collagen synthesis in human tendinous tissue. J Appl Physiol 2003: 95(6): 2390-2397.

Ireland D, Harrall RL, Holloway G, Hackney R, Hazleman BL, Riley GP. Multiple changes in gene expression in chronic human achilles tendinopathy. Matrix Biol 2001: 20(3): 159-169.

Jarvinen M, Józsa L, Kannus P, Jarvinen TLN, Kvist M, Leadbetter W. Histopathological findings in chronic tendon disorders. Scand J Med Sci Sports 1997: 7(2): 86-95.

Józsa L, Kannus P. Overuse injuries of tendons. In: Józsa L, Kannus P.. Human tendons: anatomy, physiology and pathology, 1st edn. Champaign, IL: Human Kinetics, 1997a: 164-253.

Józsa L, Kannus P. Structure and metabolism of normal tendons. In: Józsa L, Kannus P. Human tendons. Anatomy physiology and pathology, 1st edn. Champaign, IL: Human Kinetics, 1997b: 46-95.

Kannus P. Tendon pathology: basic science and clinical applications. Sports Exerc Injury 1997: 3(2): 62-75.

Kannus P. Structure of the tendon connective tissue. Scand J Med Sci Sports 2000: 10(6): 312-320.

Kannus P, Józsa L. Histopathological changes preceding spontaneous rupture 
of a tendon. A controlled study of 891 patients. J Bone Joint Surg [Am] 1991: 73-A: 1507-1525.

Kashiwagi M, Enghild JJ, Gendron C, Hughes C, Caterson B, Itoh Y, Nagase $\mathrm{H}$. Altered proteolytic activities of ADAMTS- 4 expressed by C-terminal processing. J Biol Chem 2004: 279(11): 10109-10119.

Kashiwagi M, Tortorella M, Nagase H, Brew K. TIMP-3 is a potent inhibitor of aggrecanase 1 (ADAM-TS4) and aggrecanase 2 (ADAM-TS5). J Biol Chem 2001: 276(16): 12501-12504.

Kaushal GP, Shah SV. The new kids on the block: ADAMTSs, potentially multifunctional metalloproteinases of the ADAM family. J Clin Invest 2000: 105(10): 1335-1337.

Kjaer M, Langberg H, Skovgaard D, Olesen J, Bulow J, Krogsgaard M, Boushel R. In vivo studies of peritendinous tissue in exercise. Scand J Med Sci Sports 2000: 10(6): 326-331.

Koch M, Foley JE, Hahn R, Zhou P, Burgeson RE, Gerecke DR, Gordon MK. Alpha 1(Xx) collagen, a new member of the collagen subfamily, fibril- associated collagens with interrupted triple helices. J Biol Chem 2001: 276(25): 23120-23126.

Koch M, Laub F, Zhou P, Hahn RA, Tanaka S, Burgeson RE, Gerecke DR, Ramirez F, Gordon MK. Collagen XXIV, a vertebrate fibrillar collagen with structural features of invertebrate collagens: selective expression in developing cornea and bone. J Biol Chem 2003: 278(44): 43236-43244.

Koshy PJ, Lundy CJ, Rowan AD, Porter S, Edwards DR, Hogan A, Clark IM, Cawston TE. The modulation of matrix metalloproteinase and ADAM gene expression in human chondrocytes by interleukin-1 and oncostatin M: a time-course study using real-time quantitative reverse transcriptionpolymerase chain reaction. Arthritis Rheum 2002: 46(4): 961-967.

Koskinen SO, Heinemeier KM, Olesen JL, Langberg H, Kjaer M. Physical exercise can influence local levels of matrix metalloproteinases and their inhibitors in tendon-related connective tissue. J Appl Physiol 2004: 96(3): 861-864.

Kuno K, Okada Y, Kawashima H, Nakamura H, Miyasaka M, Ohno H, Matsushima K. ADAMTS-1 cleaves a cartilage proteoglycan, aggrecan. FEBS Lett 2000: 478(3): 241-245.

Langberg H, Bulow J, Kjaer M. Blood flow in the peritendinous space of the human achilles tendon during exercise. Acta Physiol Scand 1998: 163(2): 149-153.

Langberg H, Rosendal L, Kjaer M. Training-induced changes in peritendinous type I collagen turnover determined by microdialysis in humans. J Physiol 2001: 534(Part 1): 297-302.

Langberg H, Skovgaard D, Karamouzis M, Bulow J, Kjaer M. Metabolism and inflammatory mediators in the peritendinous space measured by microdialysis during intermittent isometric exercise in humans. J Physiol 1999: 515(Part 3): 919-927.

Leadbetter WB. Cell-matrix response in tendon injury. Clin Sports Med 1992: 11: $533-578$.

Lehto M, Józsa L, Kvist M, Jarvinen M, Balint BJ, Reffy A. Fibronectin in the ruptured human achilles tendon and its paratenon an immunoperoxidase study. Ann Chir Gynaecol 1990: 79(2): 72-77.

Mackie EJ, Halfter W, Liverani D. Induction of tenascin in healing wounds. J Cell Biol 1988: 107(6, Part 2): 2757-2767.

Matrisian LM. Metalloproteinases and their inhibitors in matrix remodeling. TIG 1990: 6: 121-125.

McCawley LJ, Matrisian LM. Matrix metalloproteinases: they're not just for matrix anymore! curr. Opin Cell Biol 2001: 13(5): 534-540.

McNeilly CM, Banes AJ, Benjamin M, Ralphs JR. Tendon cells in vivo form a three dimensional network of cell processes linked by gap junctions. J Anat 1996: 189: 593-600.

Murphy G, Willenbrock F. Tissue inhibitors of matrix metalloendopeptidases. Methods Enzymol 1995: 248: 496-510.

Murphy G, Willenbrock F, Crabbe T, O'Shea M, Ward R, Atkinson S, O'Connell J, Docherty A. Regulation of matrix metalloproteinase activity. Ann N Y Acad Sci 1994: 732: 31-41.

Myllyharju J, Kivirikko KI. Collagens, modifying enzymes and their mutations in humans, flies and worms. Trends Genet 2004: 20(1): 33-43.

Nagase H. Matrix metalloproteinases. A mini-review. Contrib Nephrol 1994: 107: 85-93.

Pace JM, Corrado M, Missero C, Byers $\mathrm{PH}$. Identification, characterization and expression analysis of a new fibrillar collagen gene, COL27A1. Matrix Biol 2003: 22(1): 3-14.

Patterson-Kane JC, Wilson AM, Firth EC, Parry DAD, Goodship AE. Comparison of collagen fibril populations in the superficial digital flexor tendons of exercised and nonexercised thoroughbreds. Equine Vet J 1997: 29: 121-125.

Pierfitte C, Royer RJ. Tendon disorders with fluoroquinolones. Therapie 1996 51: 419-420.

Rees SG, Flannery CR, Little CB, Hughes CE, Caterson B, Dent CM. Catabolism of aggrecan, decorin and biglycan in tendon. Biochem J 2000: 350(Part 1): 181-188.

Riley G. The pathogenesis of tendinopathy. A molecular perspective. Rheumatology (Oxford) 2004a: 43(2): 131-142.

Riley GP. Tendon and ligament biochemistry and pathology. In: Hazleman BL, Riley GP, Speed CA Soft tissue rheumatology. Oxford: Oxford University Press, 2004b: 20-53.

Riley GP, Curry V, DeGroot J, van El B, Verzijl N, TeKoppele JM, Hazleman BL, Bank RA. Matrix metalloproteinase activities and their relationship with collagen remodelling in tendon pathology. Matrix Biol 2002: 21(2): 185-195.

Riley GP, Harrall RL, Constant CR, Cawston TE, Hazleman BL. Prevalence and possible pathological significance of calcium phosphate salt accumulation in tendon matrix degeneration. Ann Rheum Dis 1996a: 55: 109-115.

Riley GP, Harrall RL, Cawston TE, Hazleman BL, Mackie EJ. Tenascin-C and human tendon degeneration. Am J Pathol 1996b: 149: 933-943.

Riley GP, Harrall RL, Constant CR, Chard MD, Cawston TE, Hazleman BL. Tendon degeneration and chronic shoulder pain: changes in the collagen composition of the human rotator cuff tendons in rotator cuff tendinitis. Ann Rheum Dis 1994a: 53: 359-366.

Riley GP, Harrall RL, Constant CR, Chard MD, Cawston TE, Hazleman BL. Glycosaminoglycans of human rotator cuff tendons: changes with age and in chronic rotator cuff tendinitis. Ann Rheum Dis 1994b: 53: 367-376.

Samiric T, Ilic MZ, Handley CJ. Characterisation of proteoglycans and their catabolic products in tendon and explant cultures of tendon. Matrix Biol 2004a: 23(2): 127-140.

Samiric T, Ilic MZ, Handley CJ. Large aggregating and small leucine-rich proteoglycans are degraded by different pathways and at different rates in tendon. Eur J Biochem 2004b: 271(17): 3612-3620.

Sandy JD, Flannery CR, Neame PJ, Lohmander LS. The structure of aggrecan fragments in human synovial fluid. Evidence for the involvement in osteoarthritis of a novel proteinase which cleaves the Glu 373-Ala 374 bond of the interglobular domain. J Clin Invest 1992: 89: 1512-1516.

Sandy JD, Neame PJ, Boynton RE, Flannery CR. Catabolism of aggrecan in cartilage explants. identification of a major cleavage site within the interglobular domain. J Biol Chem 1991: 266(14): 8683-8685.

Sandy JD, Westling J, Kenagy RD, Iruela-Arispe $\mathrm{ML}$, Verscharen $\mathrm{C}$, 
Rodriguez-Mazaneque JC,

Zimmermann DR, Lemire JM, Fischer JW, Wight TN, Clowes AW. Versican $\mathrm{V} 1$ proteolysis in human aorta in vivo occurs at the Glu441-Ala442 bond, a site that is cleaved by recombinant ADAMTS-1 and ADAMTS- 4. J Biol Chem 2001: 276(16): 13372-13378.

Sato K, Yomogida K, Wada T, Yorihuzi T, Nishimune Y, Hosokawa N, Nagata $\mathrm{K}$. Type XXVI collagen, a new member of the collagen family, is specifically expressed in the testis and ovary. $\mathbf{J}$ Biol Chem 2002: 277(40): 37678-37684.

Smith RK, Birch H, Patterson-Kane J, Firth EC, Williams L, Cherdchutham W, van Weeren WR, Goodship AE. Should equine athletes commence training during skeletal development?: changes in tendon matrix associated with development, ageing, function and exercise. Equine Vet J 1999: 30(Suppl): 201-209.

Smith RK, Birch HL, Goodman S, Heinegard D, Goodship AE. The influence of ageing and exercise on tendon growth and degenerationhypotheses for the initiation and prevention of strain-induced tendinopathies. Comp Biochem Physiol A Mol Integr Physiol 2002: 133(4): 1039-1050.

Somerville RP, Longpre JM, Jungers KA, Engle JM, Ross M, Evanko S, Wight TN, Leduc R, Apte SS. Characterization of ADAMTS-9 and ADAMTS-20 as a distinct ADAMTS subfamily related to Caenorhabditis elegans GON-1. J Biol Chem 2003: 278(11): 9503-9513.

Tipton CM, Vailas AC, Matthes RD. Experimental studies on the influences of physical activity on ligaments, tendons and joints. Acta Med Scand 1986: 711: 157-168.
Tortorella MD, Burn TC, Pratta MA, Abbaszade I, Hollis JM, Liu R, Rosenfeld SA, Copeland RA, Decicco CP, Wynn R, Rockwell A, Yang F, Duke JL, Solomon K, George H, Bruckner R, Nagase H, Itoh Y, Ellis DM, Ross H, Wiswall BH, Murphy K, Hillman MC Jr., Hollis GF, Arner EC. Purification and cloning of aggrecanase-1: a member of the ADAMTS family of proteins. Science 1999: 284(5420): 1664-1666.

Tortorella MD, Malfait AM, Deccico C, Arner E. The role of ADAM-TS4 (aggrecanase-1) and ADAM-TS5 (aggrecanase-2) in a model of cartilage degradation. Osteoarthritis Cartilage 2001: 9(6): 539-552.

Tsuzaki M, Bynum D, Almekinders L, Yang X, Faber J, Banes AJ. ATP modulates load-inducible IL-1beta, COX 2, and MMP-3 gene expression in human tendon cells. J Cell Biochem 2003a: 89(3): 556-562.

Tsuzaki M, Guyton G, Garrett W, Archambault JM, Herzog W, Almekinders L, Bynum D, Yang X, Banes AJ. IL-1 beta induces COX2, MMP-1, -3 and -13, ADAMTS-4, IL-1 beta and IL-6 in human tendon cells. J Orthop Res 2003b: 21(2): 256-264.

Vankemmelbeke MN, Holen I, Wilson AG, Ilic MZ, Handley CJ, Kelner GS, Clark M, Liu C, Maki RA, Burnett D, Buttle DJ. Expression and activity of ADAMTS-5 in synovium. Eur J Biochem 2001: 268(5): 1259-1268.

Vogel KG, Koob TJ. Structural specialisation in tendons under compression. Int Rev Cytol 1989: 115: 267-293.

Waggett AD, Ralphs JR, Kwan APL, Woodnutt D, Benjamin M. Characterization of collagens and proteoglycans at the insertion of the human achilles tendon. Matrix Biol 1998: 16: 457-470.

Wang P, Tortorella M, England K, Malfait AM, Thomas G, Arner L, Pei D. Proprotein convertase furin interacts with and cleaves Pro-ADAMTS4 (aggrecanase-1) in the trans-Golgi network. J Biol Chem 2004: 279(15): 15434-15440.

Woo SLY, Gomez MA, Amiel D, Ritter MA, Gelberman RH, Akeson WH. The effects of exercise on the biomechanical and biochemical properties of swine digital flexor tendons. J Biomech Eng 1981: 103: 51-56.

Woo SLY, Gomez MA, Sites TJ, Newton PO, Orlando CA, Akeson WH. The biomechanical and morphological changes in the medial collateral ligament of the rabbit after immobilization and remobilization. J Bone Joint Surg Am 1987: 69(8): 1200-1211.

Woo SLY, Gomez MA, Woo Y-K, Akeson WH. Mechanical properties of tendons and ligaments: II. The relationships of immobilization and exercise on tissue remodeling. Biorheology 1982: 19: 397-408.

Yamaji N, Nishimura K, Abe K, Ohara O, Nagase T, Nomura N. Novel metalloproteinase having aggrecanase activity. European Patent 00974894.8. 11-10-2000.

Yasuda K, Hayashi K. Changes in biomechanical properties of tendons and ligaments from joint disuse. Osteoarthritis Cartilage 1999: 7(1): 122-129.

Yoshihara Y, Hamada K, Nakajima T, Fujikawa K, Fukuda H. Biochemical markers in the synovial fluid of glenohumeral joints from patients with rotator cuff tear. J Orthop Res 2001: 19(4): 573-579. 